\title{
Ecofriendly Synthesis of Silver Nanoparticles from Garden Rhubarb (Rheum rhabarbarum)
}

\author{
Palem Ramasubba Reddy, Shimoga D. Ganesh, Nabanita Saha, \\ Oyunchimeg Zandraa, and Petr Sáha
}

Centre of Polymer Systems, University Institute, Tomas Bata University in Zlin, Tř. T. Bati 5678, 76001 Zlin, Czech Republic

Correspondence should be addressed to Nabanita Saha; nabanita@ft.utb.cz

Received 23 June 2016; Accepted 24 August 2016

Academic Editor: Paresh Chandra Ray

Copyright (c) 2016 Palem Ramasubba Reddy et al. This is an open access article distributed under the Creative Commons Attribution License, which permits unrestricted use, distribution, and reproduction in any medium, provided the original work is properly cited.

\begin{abstract}
Bioreduction of silver ions following one pot process is described to achieve Rheum rhabarbarum (RR) based silver nanoparticles (SNPs) which is termed as "RR-SNPs." The Ultraviolet-visible spectroscopy (UV-vis) confirms the characteristic surface plasmon resonance band for RR-SNPs in the range of 420-460 nm. The crystalline nature of SNPs was confirmed by X-ray diffraction (XRD) peaks at $38.2^{\circ}, 45.6^{\circ}, 64.2^{\circ}$, and $76.8^{\circ}$. Transmission electron microscopy (TEM) and scanning electronic microscopy (SEM) confirm the shape of synthesized SNPs. They are roughly spherical but uniformly distributed, and size varies from 60 to $80 \mathrm{~nm}$. These biogenic SNPs show persistent zeta potential value of $34.8 \mathrm{mV}$ even after 120 days and exhibit potent antibacterial activity in presence of Escherichia coli (CCM 4517) and Staphylococcus aureus (CCM 4516). In addition, cytotoxicity of RR-SNPs against in vitro human epithelial carcinoma (HeLa) cell line showed a dose-response activity. The lethal concentration (LC50) value was found to be $28.5 \mu \mathrm{g} / \mathrm{mL}$ for RR-SNPs in the presence of HeLa cells. These findings help us to evaluate their appropriate applications in the field of nanotechnology and nanomedicine.
\end{abstract}

\section{Introduction}

Today, biosynthetic methods employing agrobased resource offer a valuable contribution in the preparation of nanoscale materials and this offers a green biochemical route toggle to the field of nanobiotechnology $[1,2]$. The environmentally benign green protocol in the synthesis of nanomaterials has overwhelmed the customary synthesis by chemical routes and finds many practical rewards such as diminishing the use of toxic chemical species and expensive surfactants [3]. Many scientific articles describe the synthesis of various nanomaterials, such as copper, gold, titanium, zinc, and silver, but silver nanoparticles (SNPs) proved their efficiency as a potent antimicrobial agent [4-10].

Colloidal nanosuspensions of silver are of special interest due to their distinctive properties like chemical stability, excellent conductivity, and catalytic and antibacterial activities [11]. The biocompatibility and nontoxicity of the plant extracts reflect the true adaptation of the green route in the synthesis of biogenic SNPs, even though various types of physicochemical methods are available [1,12-14]. A partial list of bioreduction of silver ions by selected plants and capping of the synthesized nanoparticles with various studied parameters are summarized in the Table 1. Researchers have screened various traditional medicinal plants such as Aloe vera [15, 16], Alternanthera dentata [17], Chrysopogon zizanioides [18], Dracaena Mahatma [19], Helicteres isora [20], Manilkara zapota [21], Melia azedarach [22], Mentha piperita [23], Origanum vulgare [24], Phyllanthus niruri [25], Pisonia grandis [26], Prunus $x$ yedoensis [27], Rheum australe [28], and Rheum palmatum [29] for the biosynthesis of SNPs and checked their efficacy for potent antimicrobial and cytotoxicity studies.

Typically, the virtue of medicinal and health beneficial effects of Chinese rhubarb, botanically better known as Rheum tangutucum, Rheum officinale, and Rheum palmatum, catches our attention towards rhubarb species [30]. The clinical efficacy of the rhubarb recently promotes isolate active anthraquinones such as chrysophanol, physcion, emodin, aloe emodin, and rhein by supercritical fluid chromatography 
TABLE 1: Partial list of comparative parameters reported for plant based SNPs in the literature.

\begin{tabular}{|c|c|c|c|c|c|c|c|c|}
\hline Name of plant & Source & $\begin{array}{l}\text { Size of SNPs } \\
(\mathrm{nm})\end{array}$ & $\begin{array}{c}\text { UV-Vis range } \\
(\mathrm{nm})\end{array}$ & $\begin{array}{c}\text { Antimicrobial } \\
\text { activity }\end{array}$ & Cytotoxicity & $\begin{array}{c}\text { Zeta potential } \\
(\mathrm{mv})\end{array}$ & $\mathrm{DLS}(\mathrm{nm})$ & References \\
\hline Aloe vera & Leaf & 500 & 400 & Present & NR & NR & NR & {$[15]$} \\
\hline Alternanthera sessilis & Leaf & $10-30$ & $420-450$ & NR & Effective & NR & NR & {$[16]$} \\
\hline Alternanthera dentate & Leaf & $50-100$ & 430 & Present & NR & NR & NR & [17] \\
\hline Chrysopogon zizanioides & Leaf & $85-110$ & 420 & NR & NR & NR & NR & {$[18]$} \\
\hline Dracaena Mahatma & Leaf & NR & 421 & Present & NR & -31.1 & 87.1 & [19] \\
\hline Helicteres isora & Root & $16-95$ & $420-450$ & Present & NR & 20.6 & 86.2 & [20] \\
\hline Manilkara zapota & Leaf & $70-140$ & 421 & NR & Effective & NR & NR & {$[21]$} \\
\hline Melia azedarach & Leaf & NR & 436 & 436 & Effective & -24.9 & 78 & {$[22]$} \\
\hline Mentha piperita & Leaf & 90 & 450 & NR & Effective & NR & NR & {$[23]$} \\
\hline Origanum vulgare & Leaf & $63-85$ & 440 & Present & Effective & -26 & 136 & {$[24]$} \\
\hline Phyllanthus niruri & Leaf & NR & 420 & Present & NR & NR & 63 & {$[25]$} \\
\hline Pisonia grandis & Leaf & 150 & 421 & NR & NR & NR & NR & {$[26]$} \\
\hline Prunus $x$ yedoensis & Leaf & $20-70$ & 436 & Present & NR & NR & NR & [27] \\
\hline Rheum australe & Rhizome & 100 & 410 & NR & Effective & NR & NR & {$[28]$} \\
\hline Rheum palmatum & Root & $84-130$ & 420 & Present & Effective & -21.6 & 121 & [29] \\
\hline Rheum rhabarbarum & Stem & $60-80$ & $420-460$ & Present & Effective & 34.8 & 65 & Present work \\
\hline
\end{tabular}

$\mathrm{NR}=$ not reported.

[31]. However, red-stalked rhubarb specifically recognized as Garden Rhubarb (Rheum rhabarbarum: RR) is an edible species in European countries and United Kingdom and, in some parts of North America, it is used specifically in pizza and custard sweets. RR is a species of plant in the Polygonaceae family, found to be enriched in similar anthraquinones including mainly rhein and emodin, which impart cathartic and laxative properties [32].

In recent years, there have been a multitude of new simple green methodologies established to aid in the development of metal nanoparticles with suitable advanced sensory applications [33]. SNPs can be used to afford conductive coatings for transparent conductors and flexible electronics with suitable composite materials. SNPs fastened with metallic nanowires enhance the plasmonic activity for sensing and imaging applications and deserve closer attention in device fabrications [34]. The intriguing properties of SNPs and the wide range technological interests have been an ever increasing stimulus to fully focus on specialized applications such as electrochemical sensors [35], biomedical materials, optics, and microelectronics [36]. Recently, pectin mediated synthesis of stabilized SNPs and dual responsive pectin hydrogels were prepared in sort of drug delivery applications [37]. It is certainly better to use mild plant mediated biosynthesis of nanoparticles and it is gaining importance due to advancement in chemical and physical methods, as the green approach does not involve high pressure and energy and toxic chemicals [38].

The reported RR is phytochemically distinct from Chinese rhubarb. Up to date, there is no report on synthesis of SNPs utilizing aqueous stem extracts of RR. The present articles focus on the bioreduction of aqueous solution of silver nitrate $\left(\mathrm{AgNO}_{3}\right)$ by aqueous edible $\mathrm{RR}$ stem extract, which results in the reduction of silver ions $\left(\mathrm{Ag}^{+}\right)$and formation of Rheum rhabarbarum based silver nanoparticles termed as "RR-SNPs." The disclosed green method is beneficial because the methodology is simple, effective, rapid, and easily operable in bulk without much capital expenditure. Synthesized biogenic RR-SNPs are well characterized from various spectroscopic techniques. The present biogenic SNPs possess beneficial cytotoxic responses due to their smaller dimensions and practically spherical morphology, which promote their contribution in the application of bionanotechnology and nanomedicine.

\section{Materials and Methods}

2.1. Materials. Silver nitrate $\left(\mathrm{AgNO}_{3}\right)$ was procured from Sigma Aldrich Chemicals. All the culture media for antimicrobial test were purchased from HiMedia and all other reagents were of analytical grade and used without further purification. Fresh rhubarb stems were purchased from open market in Zlin, Czech Republic. Dimethyl sulfoxide (DMSO) and 3-(4,5-dimethyldiazol-2-yl)-2,5-diphenyl tetrazolium bromide (MTT) were purchased from Merck, Germany, and Calbiochem, USA, respectively, for the assay of anticancer activity. HeLa cells were procured from Department of Virology, Slovak Academy of Sciences, Bratislava. Double Distilled Water (DDW) was used throughout the study.

\subsection{Synthesis of Biogenic Silver Nanoparticles}

2.2.1. Preparation of Aqueous Stem Extract (RR). $20 \mathrm{~g}$ of fresh rhubarb stems is washed with stream of water to remove adhered inorganics and dust impurities. The chopped stems $(2 \mathrm{~cm})$ were added to $100 \mathrm{~mL}$ of DDW and heated to $60^{\circ} \mathrm{C}$ for $1 \mathrm{~h}$. The pink turbid solution was filtered through sterilized 
cellulose membranes of porosity of $\approx 11 \mu \mathrm{m}$. The collected light-pink stem extract was designated as RR and stored at $4^{\circ} \mathrm{C}$ for further use, that is, for SNPs synthesis as bioreductant.

2.2.2. Synthesis of RR-SNPs. To synthesize RR-SNPs, $1 \mathrm{mM}$ of $\mathrm{AgNO}_{3}$ solution was mixed with stem extract (RR) in the volume ratio of $1: 2$ and stirred occasionally at $200 \mathrm{rpm}$ over a period of $30 \mathrm{~min}$ at room temperature $\left(\approx 18-20^{\circ} \mathrm{C}\right)$. The formation of colloidal SNPs was observed and it is perceived by the color change from pink to brown. Afterwards, they were kept in dark for $24 \mathrm{~h}$. Then, they were centrifuged using Heraeus Multifuge X1R (Thermo Scientific, Germany) at room temperature and they achieved biogenic SNPs. Finally, these obtained SNPs are termed as "RR-SNPs." The purification was done by repeated centrifugation at $10000 \mathrm{rpm}$. The experiments were repeated by redispersion of the SNPs in 10-20 mL of DDW, and the SNPs were collected by centrifugation. The freeze-dried SNPs are then grinded and collected as brown powder.

\subsection{Characterization}

2.3.1. UV-Visible (UV-Vis) Spectroscopy Analysis. Bioreduction of the $\mathrm{AgNO}_{3}$ to RR-SNPs by bioreductant aqueous RR was monitored using UV-Vis Spectrophotometer (VARIAN-EL08043361). The samples used for analysis were subsequently measured in the ultraviolet-visible spectrum at regular time intervals. Samples were loaded into a $1 \mathrm{~cm}$ path length quartz cuvette for the measurement. The spectrum was scanned from $200 \mathrm{~nm}$ to $800 \mathrm{~nm}$.

2.3.2. Fourier Transform Infrared Spectroscopy (FTIR). The purified and freeze-dried RR-SNPs and RR were characterized by FTIR spectroscopy (Nicolet 6700, ATR) in the scanning range $4000-600 \mathrm{~cm}^{-1}$. The resolution was $4 \mathrm{~cm}^{-1}$ with 64 scans and the measurement was done with Germanium crystal.

2.3.3. Dynamic Light Scattering (DLS). The average particle size, size distribution, and zeta potentials of RR-SNPs in colloidal suspension were evaluated by using dynamic light scattering experiments. It measures the Brownian motion and relates this to the size of the particles. The nanosize measurements were performed using the Zetasizer (Nano ZS, Malvern, UK). The measurement was repeated in triplicate at a fixed angle of $173^{\circ}$ at $25^{\circ} \mathrm{C}$. Furthermore, the electrophoretic velocity of RR-SNPs was evaluated using the zeta potential values.

2.3.4. Scanning Electron Microscopy (SEM). The morphological features of the RR-SNPs were investigated by recording their scanning electron micrographs (FEI, Nova NanoSEM450, Netherlands) at different magnification with accelerating voltage of $5 \mathrm{kV}$.

2.3.5. Transmission Electron Microscopy (TEM). The samples for TEM measurements were done by placing a drop of the colloidal suspension of RR-SNPs on carbon-coated copper grids and dried prior to measurement for $2 \mathrm{~h}$ at $60^{\circ} \mathrm{C}$. The images of SNPs were taken on a TEM, FEI Technai F20, operated at accelerating voltage $200 \mathrm{kV}$, and equipped with an energy-dispersive X-ray spectrometer.

2.3.6. Thermal Gravimetric Analysis (TGA). Thermogravimetric analysis was performed by using a thermogravimetric analyzer TA Q500 (TA Instruments, USA). The weight loss of material was determined at heating rate of $10^{\circ} \mathrm{C} / \mathrm{min}$ in temperature range from 25 to $600^{\circ} \mathrm{C}$ under inert atmosphere ( $\mathrm{N}_{2}$ purge flow $50 \mathrm{~mL} / \mathrm{min}$; initial sample weights were about $14 \pm 0.3 \mathrm{mg})$.

2.3.7. X-Ray Diffraction (XRD). The XRD patterns of RR and RR-SNPs were obtained using X-ray diffractometer (PANalytical X'Pert PRO) equipped with PIXcel detector and $\mathrm{CuK} \alpha(l=1.540 \AA)$ radiation in a $\theta-2 \theta$ configuration. The diffraction angle was varied in the range of $10-90^{\circ}$, while the scanning rate was $0.026 / \mathrm{min}$, operating at a voltage of $40 \mathrm{kV}$ and a current of $30 \mathrm{~mA}$.

2.4. Antibacterial Assay. The antibacterial activity of RRSNPs was tested against two bacterial strains: Escherichia coli (E. coli, CCM 4517) and Staphylococcus aureus (S. aureus, CCM 4516). The study was conducted in a sterile nutrient agar $(2.5 \%)$ medium, which was sterilized (at $120^{\circ} \mathrm{C}$, $15 \mathrm{lb}$ for $20 \mathrm{~min}$ ), then poured into the sterile Petri plates $(80 \mathrm{~mm})$, and then allowed to become solid. The inoculum (i.e., bacterial cells suspension of E. coli and S. aureus) was prepared individually for each bacterial strain under aseptic condition. Thereafter, each of the nutrient agar plates was flooded with these two bacterial culture separately. After that, four round $(8 \mathrm{~mm})$ agar blocks were removed from each of the Petri plates. $100 \mu \mathrm{L}$ of the RR (control) and three different concentrations of RR-SNPs (test sample) were placed in the hole of $8 \mathrm{~mm}$ dimension (depicted in Table 2 and Figure S3 in Supplementary Material available online at http://dx.doi.org/10.1155/2016/4964752). The plates were then incubated at $37^{\circ} \mathrm{C}$ for $48 \mathrm{~h}$ to evaluate the antibacterial activity of RR-SNPs.

2.5. Anticancer Activity. The anticancer activity of RR-SNPs (test sample) and RR (negative control) was investigated in presence of HeLa cells. Before performing anticancer activity test, the RR-SNPs and RR were sterilized and filtered through $0.22 \mu \mathrm{m}$ filter bed. On the other hand, HeLa cells, at concentration of 5000 cells per well, were seeded in 96-tissue culture plate and incubated overnight at $37^{\circ} \mathrm{C}$ in the $\mathrm{CO}_{2}$ incubator $\left(5 \% \mathrm{CO}_{2}\right)$. Thereafter, the said RR-SNPs and RR were placed into HeLa cells at different concentrations $(10,50,100,150,200,250$, and $500 \mu \mathrm{g} / \mathrm{mL})$ and incubated again at $37^{\circ} \mathrm{C}$ in $5 \% \mathrm{CO}_{2}$ atmosphere until 72 hours. After that, test samples were collected every $24 \mathrm{~h}$ interval and then the medium was removed and replaced with a freshly prepared growth medium (100 $\mu \mathrm{L}$ of DMSO) with MTT at concentration of $0.5 \mathrm{mg} / \mathrm{mL}$ and incubated at $37^{\circ} \mathrm{C}, 5 \% \mathrm{CO}_{2}$ for $2 \mathrm{~h}$. Afterwards, the absorbance of DMSO extraction was measured using the plate reader (DYNEX MRXII) at the wavelength of $595 \mathrm{~nm}$. The cell viability was determined spectrophotometrically by comparing the absorbance of 
TABLE 2: Antibacterial activity results of RR and RR-SNPs.

\begin{tabular}{|c|c|c|c|c|c|}
\hline \multirow{3}{*}{ Serial no } & \multirow{3}{*}{ Test sample } & \multicolumn{4}{|c|}{ Zones of inhibition (mm) } \\
\hline & & \multicolumn{2}{|c|}{ S. aureus } & \multicolumn{2}{|c|}{ E. coli } \\
\hline & & After $24 \mathrm{~h}$ & After $48 \mathrm{~h}$ & After $24 \mathrm{~h}$ & After $48 \mathrm{~h}$ \\
\hline $\bar{I}$ & (E) RR & 0 & 0 & 0 & 0 \\
\hline II & (1) RR-SNPs $1^{*}$ & 2.6 & 3.4 & 2.3 & 3.3 \\
\hline III & (2) RR-SNPs $2^{*}$ & 6.6 & 7.3 & 4.0 & 7.6 \\
\hline IV & (3) RR-SNPs $3^{*}$ & 8.7 & 9.8 & 10.6 & 10.8 \\
\hline
\end{tabular}

${ }^{*}$ RR-SNPs 1: composition (RR $4 \mathrm{~mL}+5 \mu \mathrm{L} \mathrm{AgNO}_{3}$ ); RR-SNPs 2: composition (RR $4 \mathrm{~mL}+10 \mu \mathrm{L} \mathrm{AgNO}_{3}$ ); RR-SNPs 3: composition $(\mathrm{RR} 4 \mathrm{~mL}+15 \mu \mathrm{L}$ AgNO 3 ).

treated and untreated cells (negative control). The data are presented (as mean $\pm n=6$ ) in Figure 6.

\section{Results and Discussion}

3.1. UV-Visible Spectroscopy Analysis. In order to check the efficacy of the bioreductant (RR), UV-Vis experiments were carried out. After optimizing the results, in respect to yield of SNPs and UV-Vis absorption peaks, the optimum silver ion concentration was fixed (i.e., $1 \mathrm{mM}$ ). Three different combinations of $\mathrm{RR}$ and $\mathrm{AgNO}_{3}$ mixer were prepared to evaluate the efficiency of RR for the formation of SNPs. Figures 1(a), $1(b)$, and 1(c) represent the UV-visible absorption spectra of RR-SNPs variation with $\mathrm{RR}$ and $\mathrm{AgNO}_{3}$. It can be seen from the UV-Vis spectra that the observed intense absorption peak in the range of $420-460 \mathrm{~nm}$, was due to surface plasmon excitation of SNPs.

In Figure 1(a), the stoichiometric volume ratio of $\mathrm{AgNO}_{3}$ solution from $50 \mu \mathrm{L}$ to $300 \mu \mathrm{L}(1: 80,1: 40,1: 20$, and $1: 10)$ was varied with the constant volume of RR (i.e., $4 \mathrm{~mL}$ ). The surface plasmon excitation was observed at $455 \mathrm{~nm}$ and results indicate that the size of SNPs can be controlled by optimizing the amount of silver ions. In Figure 1(b), the RR was varied from $1 \mathrm{~mL}$ to $6 \mathrm{~mL}$ keeping the volume of $\mathrm{AgNO}_{3}$ solution constant (i.e., $250 \mu \mathrm{L}$ ). Here, it can be seen that as the volume of the RR (a bioreductant) increases, the SPR band shifted towards the longer wavelength region signifying the formation of RR-SNPs with higher dimensions. For the composition of $5 \mathrm{~mL}$ of RR with $250 \mu \mathrm{L}$ of $\mathrm{AgNO}_{3}$ solution, the observed RR-SNPs formation is less, due to the depletion of the $\mathrm{Ag}^{+}$ions by RR. Finally, subsequent variation of both RR ( $0.5 \mathrm{~mL}$ to $3.5 \mathrm{~mL})$ and $\mathrm{AgNO}_{3}$ solution $(3.5 \mathrm{~mL}$ to $0.5 \mathrm{~mL}$ ) was examined and depicted in Figure 1(c). It has also been noticed that bathochromicity of the SPR band width with increase in volume of silver ions signifies the formation of high dimensional SNPs.

To evaluate the stability of RR-SNPs, the UV-visible absorption spectra of RR-AgNO $\mathrm{N}_{3}$ mixture $(1: 80,1: 40,1: 20$, and 1:10) keeping the volume of $\mathrm{RR}$ as constant were measured after 30 and 120 days (see Figure 2), respectively. A wavelength shift of $435 \mathrm{~nm}$ from $455 \mathrm{~nm}$ was observed for RRSNPs after 30 days as well as 120 days. There is no noticeable change in the position of peaks on 120th day (Figure 2); this clearly indicates that the formed RR-SNPs do not agglomerate and RR serves as an effective stabilizing agent for the SNPs.
3.2. Fourier Transforms Infrared Analysis. The FTIR analysis was carried out to identify the possible functional groups present in $\mathrm{RR}$, responsible for the reduction of silver ions $\left(\mathrm{Ag}^{+}\right)$to SNPs $\left(\mathrm{Ag}^{\circ}\right)$. The bands at $3240 \mathrm{~cm}^{-1}$ and $1237 \mathrm{~cm}^{-1}$ correspond to the $\mathrm{O}-\mathrm{H}$ stretching and $\mathrm{C}-\mathrm{O}$ stretching of benzene ring containing acids and/or alcohol compounds (like quinones, emodin, and rhein), respectively. The peaks at 1700 and 2912 and $2876 \mathrm{~cm}^{-1}$ signify the $\mathrm{C}=\mathrm{O}$ stretching of ketones and/or acids and $\mathrm{C}-\mathrm{H}$ stretching $\left(-\mathrm{CH}_{2} /-\mathrm{CH}_{3}\right)$ of aliphatic bands, respectively.

The bands at $872 \mathrm{~cm}^{-1}$ and $777 \mathrm{~cm}^{-1}$ can be assigned to the $\mathrm{C}-\mathrm{H}$ bending of alkenes and alkanes, respectively. A strong $\mathrm{C}-\mathrm{C}$ stretching band vibration at $1300 \mathrm{~cm}^{-1}$ was observed in addition to $720 \mathrm{~cm}^{-1}$ band for $\mathrm{C}-\mathrm{Cl}$ stretching, which is due to alkyl halide (Figure 3). The quinones are the major water-soluble phytochemicals that are responsible for the immediate reduction of the $\mathrm{AgNO}_{3}$ solution. They undergo tautomerization, leading to the formation of the SNPs [39].

3.3. Particle Size, XRD, and Electron Microscopy Analysis. Representative histogram displayed in Figure S1d (see Supplementary Material) showed that the particles are distributed in the range of $15-170 \mathrm{~nm}$ and majority of the particles are in the range of $60-80 \mathrm{~nm}$. The polydispersity index (PI) value for the colloidal suspension is 0.196 , indicating that the size distribution of RR-SNPs is nanoscopic. This was further supported by SEM and TEM studies; SEM and TEM were shown in Supplementary Material, from which the average mean size of the RR-SNPs is $\approx 50 \mathrm{~nm}$ and seems to be roughly spherical in morphology (see Figures Sla and S1b).

In Figure 4, the XRD pattern clearly shows that the RR-SNPs are crystalline in nature. The major diffraction peaks for RR-SNPs at $38.2,45.6,64.2$, and $76.8^{\circ}$ could be attributed to (111), (200), (220), and (311) crystallographic planes, thereby confirming the formation of SNPs. Due to the crystallization of bioorganic phase on the SNPs, the observation of diffraction peak at $23.5^{\circ}$ has been noticed. The diffraction pattern reflects the crystalline nature of RR-SNPs [40]. The EDX spectrum displayed in Figure S1c (Supplementary Material) shows strong signal at $3 \mathrm{keV}$, which is the typical absorption pattern of metallic nanocrystalline silver surface, and indicates the presence of SNPs. In addition, weak signals for $\mathrm{Cl}, \mathrm{K}, \mathrm{P}$, and $\mathrm{S}$ elements were also noticed.

The zeta potential and electrophoretic mobility distribution of RR-SNPs that were observed on 120th day, $34.8 \pm 1.5 \mathrm{mV}$, were presented in Supplementary Material 


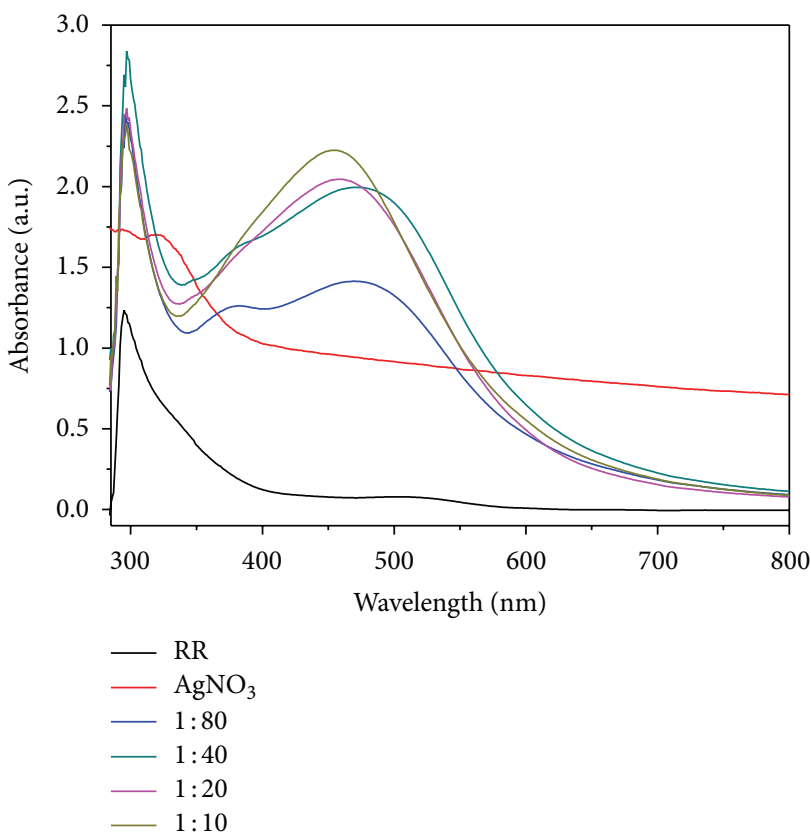

(a)

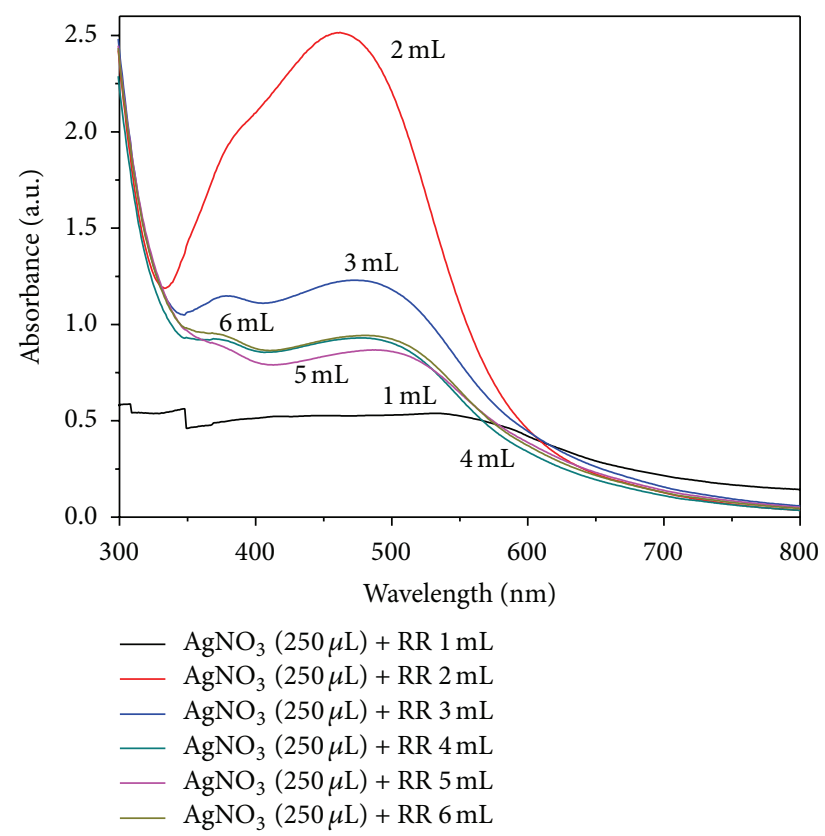

(b)

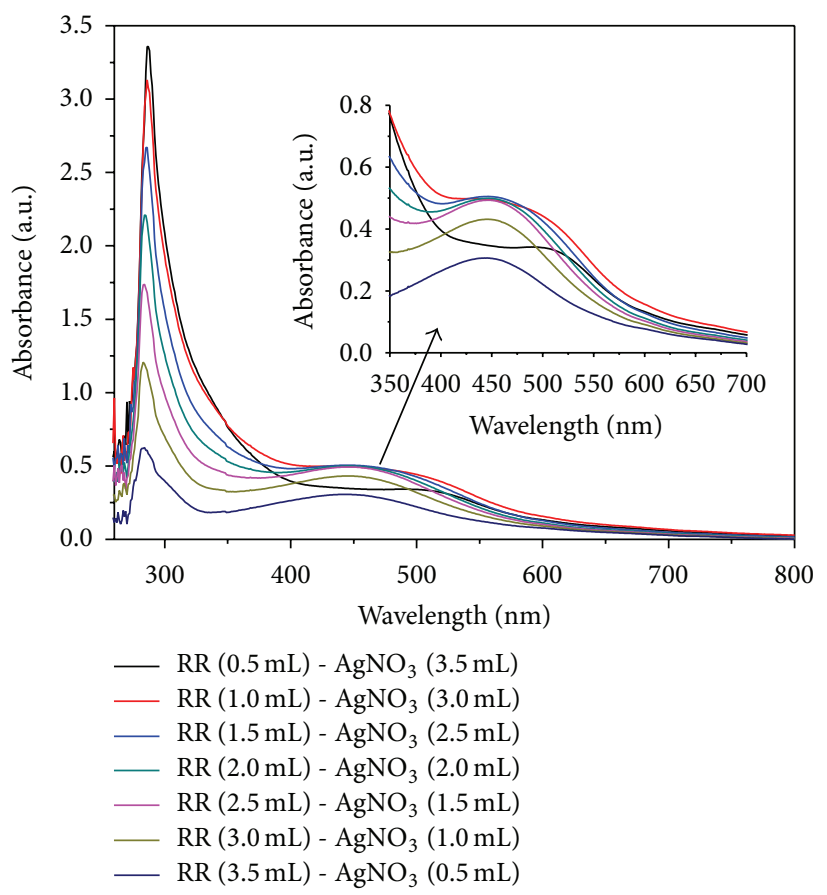

(c)

FIgURE 1: Variation of UV-visible spectra of RR-SNPs obtained using stem extract of Rheum rhabarbarum (RR) with (a) volume of AgNO , (b) volume of $\mathrm{RR}$, and (c) volume of both $\mathrm{RR}$ and $\mathrm{AgNO}_{3}$.

(Figures S2a and S2b). It indicates that SNPs comprising RR are stable and prevent agglomeration for longer duration. It is reported that SNPs from Dracaena Mahatma [19], Helicteres isora [20], Melia azedarach [22], and Origanum vulgare [24] show excellent zeta potential stability. Similar zeta potential values of RR-SNPs have also been noticed in the present work, which are significantly high and quite stable up to 120 days.
3.4. Thermal Gravimetric Analysis. The thermal stability of RR and RR-SNPs was studied using TGA and dramatically carried out between temperatures and weight loss in (\%) as given in Figure 5. The experimental results showed 3.10, $6.73,29.27,18.28$, and $5.26 \%$ degradation of RR: they show weight loss in five steps and total weight loss of $37.35 \%$ was observed and $62.65 \%$ of residue remained in the alumina crucible. However, degradation of RR-SNPs was observed in 


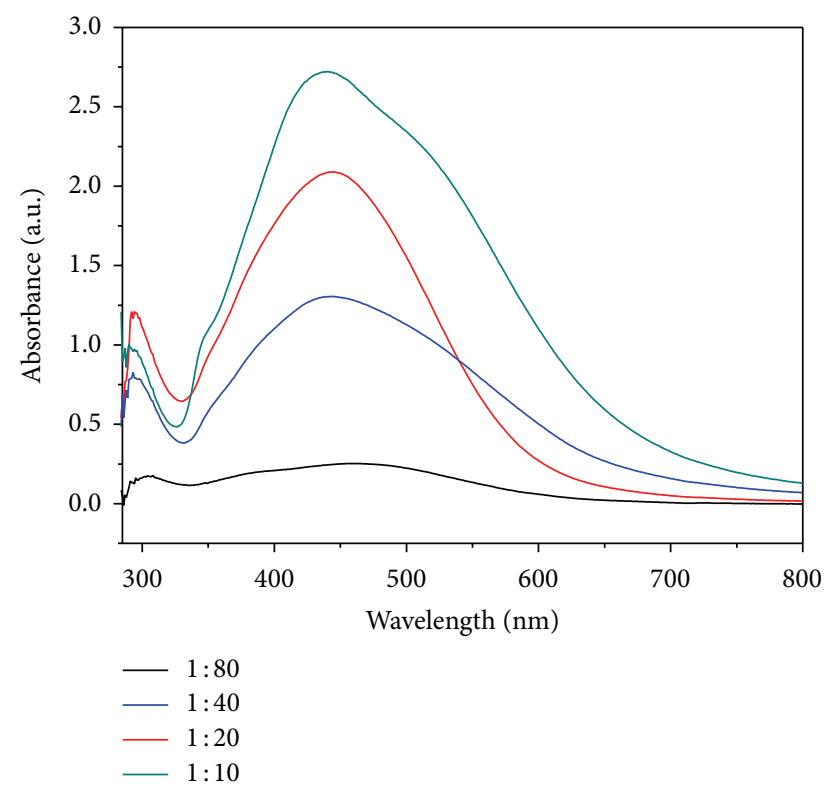

FIGURE 2: UV-visible absorption spectra of RR-SNPs on 120th day after preparation (variation of $\mathrm{AgNO}_{3}$ in accordance with $4 \mathrm{~mL}$ of $\mathrm{RR})$.

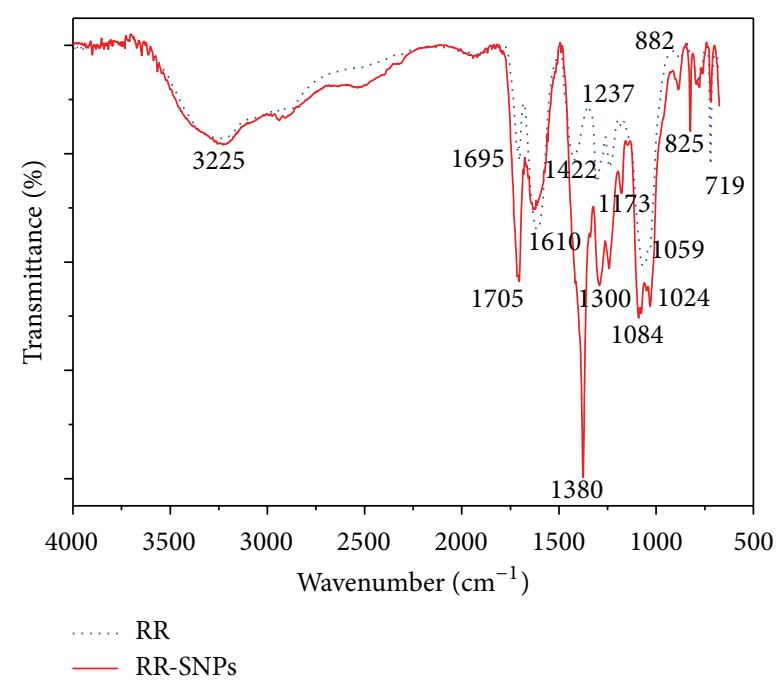

FIGURE 3: FTIR spectra of freeze-dried powder samples of RR and RR-SNPs.

four weight loss stages, that is, $7.24,26.24,19.04$, and $1.05 \%$. The total weight loss observed for RR-SNPs was $46.42 \%$ and $53.58 \%$ of residue remained in the alumina crucible. The first step of degradation in RR and RR-SNPs observed due to the evaporation of adsorbed water molecules. The complete degradation of RR has occurred in the fourth step, while RR-SNPs occurred in the third step. This observation is most likely a consequence of the surface desorption of bioorganic compounds present in the RR-SNPs. Accordingly, stem extract stabilized SNPs are expected to be made up of molecules responsible for the reduction of metal ion and stabilizing the particles in the solution. The difference in

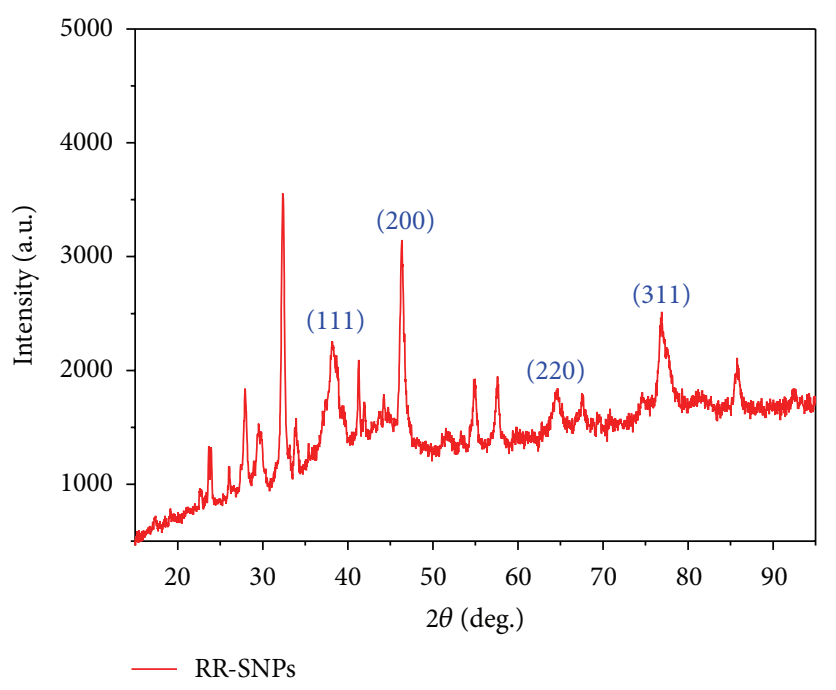

FIGURE 4: XRD pattern of biogenic RR-SNPs.

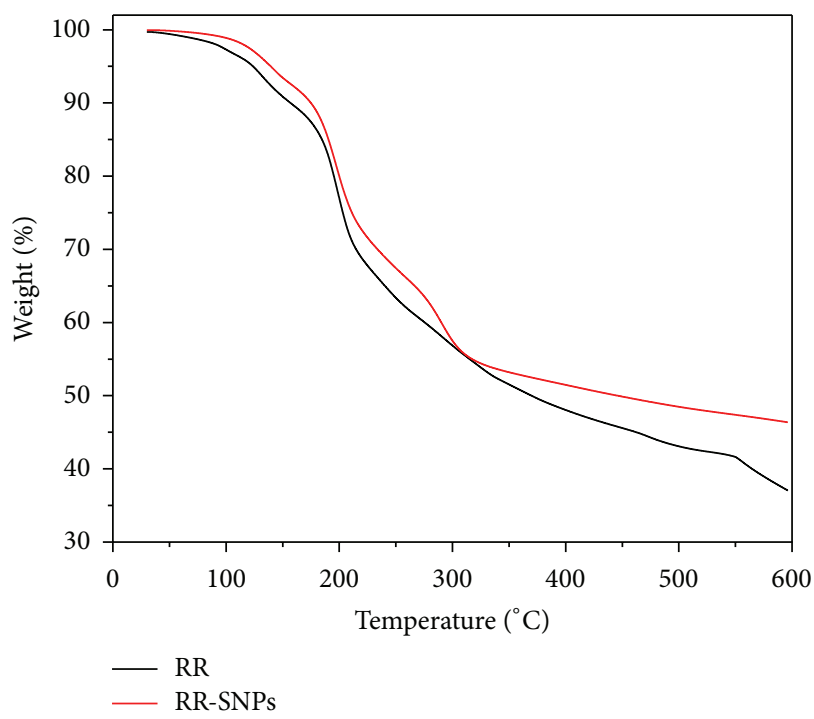

FIGURE 5: TGA thermograms of RR and RR-SNPs at a heating rate of $10^{\circ} \mathrm{C} / \mathrm{min}$ under $\mathrm{N}_{2}$ atmosphere.

decomposition between the RR and RR-SNPs is found to be $10 \%$, and it confirms the presence of SNPs in the RR.

3.5. Antibacterial Activity of RR-SNPs. For evaluating the antibacterial/antimicrobial activity of RR-SNPs, S. aureus and E. coli are selected as these are common pathogen of human body. See Figure S3 in Supplementary Material; the figure shows the zones of inhibition produced by RR and SNPs comprising RR in presence of $S$. aureus and E. coli. The aqueous RR-SNPs suspensions of three varied compositions of $\mathrm{AgNO}_{3}(5 \mu \mathrm{L}, 10 \mu \mathrm{L}$, and $15 \mu \mathrm{L}$ were designated as samples 1, 2 and 3, resp.) could inhibit the growth of bacterial strains as shown in Table 2. However, no change in the zone of inhibition was observed during 6 days of the incubation period. 


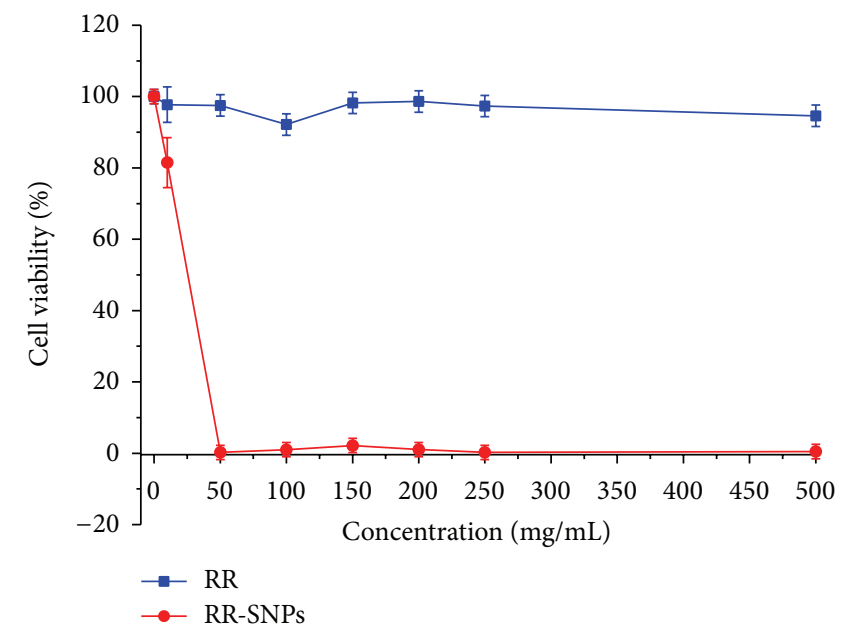

(a)

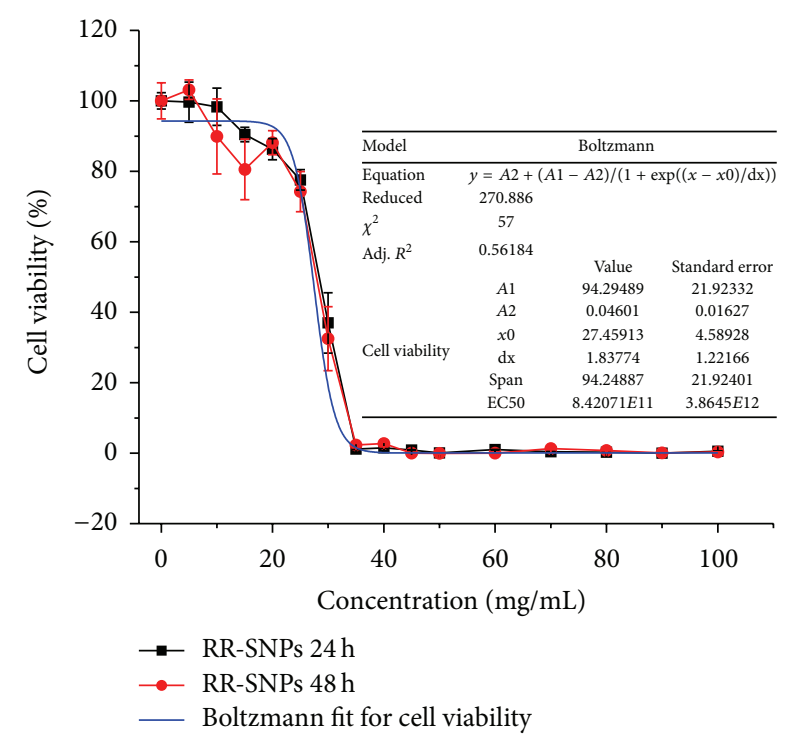

(b)

Figure 6: Anticancer activity of (a) RR and RR-SNPs on HeLa cell lines after $24 \mathrm{~h}$ of incubation and (b) RR-SNPs on HeLa cell lines after $24 \mathrm{~h}$ and $48 \mathrm{~h}$ of incubation.

3.6. Anticancer Activity of RR-SNPs. Anticancer activity of RR-SNPs was performed in presence of HeLa cell lines. HeLa cells were cultured at humidified atmosphere $\left(5 \% \mathrm{CO}_{2}\right)$ at $37^{\circ} \mathrm{C}$. Cells were cultured and were seeded in to 96-tissue culture plates and incubated for $24 \mathrm{~h}$ in the aforementioned incubation conditions. The tested materials were dispersed in the full growth medium at concentration of $1 \mathrm{mg} / \mathrm{mL}$. The sonicated samples of RR-SNPs were sterile filtered through $0.22 \mu \mathrm{m}$ filter and incubated at different concentrations ( 0 $100 \mu \mathrm{g} / \mathrm{mL}$ ) for $24 \mathrm{~h}$ and $48 \mathrm{~h}$. After the incubation, the medium was replaced with medium containing MTT at concentration of $0.5 \mathrm{mg} / \mathrm{mL}$ and incubated again for additional $2 \mathrm{~h}$. Afterwards, MTT medium was removed and $100 \mu \mathrm{L}$ of DMSO was added. The absorbance was measured by plate reader at the wavelength of $595 \mathrm{~nm}$. OD value was subjected to sort-out percentage of viability by using the following formula of OD value of experimental samples (RR-SNPs):

$\%$ of Viability

$$
=\frac{\mathrm{OD} \text { value of experimental samples (RR-SNPs) }}{\text { OD value of experimental control (untreated) }}
$$

$\times 100$.

The RR has no effect on cell viability in the tested concentration range as shown in Figure 6(a). Whereas RRSNPs show cytotoxic effect on HeLa cells, $50 \%$ of the cells were survived after $24 \mathrm{~h}$ incubation based on the fitting curve. The rest of surviving cells proliferate as seen after $48 \mathrm{~h}$ by increase in $\mathrm{OD}$, but, compared to control, the $\mathrm{LC}_{50}$ stays at $28.5 \mu \mathrm{g} / \mathrm{mL}$ (Figure 6(b)).

\section{Conclusion}

The development of metallic nanoparticles is inexpensive using plant mediated green methods and specifically provides controlled size and morphology. The nanoparticles must be free of toxic contaminants as required in therapeutic applications in the field of nanomedicine. In this context, facile green protocol for the synthesis of SNPs using RR extract has been demonstrated at room temperature. We have shown that the aqueous stem extract of Garden Rhubarb (Rheum rhabarbarum) can be used as bioreductant and stabilizer for the efficient synthesis of SNPs. The SNPs formation was confirmed by various spectroscopic analysis: UV-visible, FTIR, and XRD analysis, and size of the particles was studied by DLS and TEM analysis. The zeta potential value $34.8 \mathrm{mV}$ for RR-SNPs indicates the stability of nanoparticles and lower aggregation over a period of 120 days. The antibacterial activity of RR-SNPs is potent towards Gram-positive (+ve) strains of Staphylococcus aureus (S. aureus) and Gramnegative (-ve) strains of Escherichia coli (E. coli). The lethal concentration $\left(\mathrm{LC}_{50}\right)$ value for RR-SNPs was found to be $28.5 \mu \mathrm{g} / \mathrm{mL}$ against HeLa cell line. Furthermore, RR-SNPs show significant antibacterial action on tested pathogenic (S. aureus and E. coli) microorganisms. As a result, it is observed that the fine tuning in the process variables and pharmaceutical formulations of these biogenic RR-SNPs could be of great interest in the field of nanobiotechnology and nanomedicine.

\section{Disclosure}

It is to state that neither authors nor their institution has a financial or other relationships with any organization or people that may influence the author's work. Authors are not being paid by any organization or agency related to the product. 


\section{Competing Interests}

There are no competing interests to be declared.

\section{Acknowledgments}

The work was supported by the Ministry of Education, Youth and Sports of the Czech Republic-NPU Program I (LO1504). Authors are grateful to Dr. Zuzana Kronekova, Polymer Institute, Slovak Academy of Sciences, Bratislava, for studying the anticancer activity of RR-SNPs. Authors are also grateful to Department of Material Science and Nanotechnology, IISc Bangalore, India, for TEM analysis.

\section{References}

[1] H. P. Borase, B. K. Salunke, R. B. Salunkhe et al., "Plant extract: a promising biomatrix for ecofriendly, controlled synthesis of silver nanoparticles," Applied Biochemistry and Biotechnology, vol. 173, no. 1, pp. 1-29, 2014.

[2] P. Malik, R. Shankar, V. Malik, N. Sharma, and T. K. Mukherjee, "Green chemistry based benign routes for nanoparticle synthesis," Journal of Nanoparticles, vol. 2014, Article ID 302429, 14 pages, 2014.

[3] T. M. D. Dang, T. T. T. Le, E. Fribourg-Blanc, and M. C. Dang, "Influence of surfactant on the preparation of silver nanoparticles by polyol method," Advances in Natural Sciences: Nanoscience and Nanotechnology, vol. 3, no. 3, Article ID 035004, 2012.

[4] P. Velusamy, J. Das, R. Pachaiappan, B. Vaseeharan, and K. Pandian, "Greener approach for synthesis of antibacterial silver nanoparticles using aqueous solution of neem gum (Azadirachta indica L.)," Industrial Crops and Products, vol. 66, no. 1, pp. 103-109, 2015.

[5] T. Suwatthanarak, B. Than-ardna, D. Danwanichakul, and P. Danwanichakul, "Synthesis of silver nanoparticles in skim natural rubber latex at room temperature," Materials Letters, vol. 168, pp. 31-35, 2016.

[6] S. S. Sana, V. R. Badineni, S. K. Arla, and V. K. N. Boya, "Ecofriendly synthesis of silver nanoparticles using leaf extract of Grewia flaviscences and study of their antimicrobial activity," Materials Letters, vol. 145, pp. 347-350, 2015.

[7] P. Logeswari, S. Silambarasan, and J. Abraham, "Synthesis of silver nanoparticles using plants extract and analysis of their antimicrobial property," Journal of Saudi Chemical Society, vol. 19, no. 3, pp. 311-317, 2015.

[8] A. M. Alkilany, S. E. Lohse, and C. J. Murphy, "The gold standard: gold nanoparticle libraries to understand the nanobio interface," Accounts of Chemical Research, vol. 46, no. 3, pp. 650-661, 2013.

[9] A. Weir, P. Westerhoff, L. Fabricius, K. Hristovski, and N. Von Goetz, "Titanium dioxide nanoparticles in food and personal care products," Environmental Science and Technology, vol. 46, no. 4, pp. 2242-2250, 2012.

[10] R. W. Raut, N. S. Kolekar, J. R. Lakkakula, V. D. Mendhulkar, and S. B. Kashid, "Extracellular synthesis of silver nanoparticles using dried leaves of Pongamia pinnata (L) pierre," Nano-Micro Letters, vol. 2, no. 2, pp. 106-113, 2010.

[11] A. Frattini, N. Pellegri, D. Nicastro, and O. de Sanctis, "Effect of amine groups in the synthesis of Ag nanoparticles using aminosilanes," Materials Chemistry and Physics, vol. 94, no. 1, pp. 148-152, 2005.
[12] C. Rajkuberan, S. Prabukumar, G. Sathishkumar, A. Wilson, K. Ravindran, and S. Sivaramakrishnan, "Facile synthesis of silver nanoparticles using Euphorbia antiquorum L. latex extract and evaluation of their biomedical perspectives as anticancer agents," Journal of Saudi Chemical Society, 2016.

[13] G. C. J. Swarnavalli, S. Dinakaran, N. Raman, R. Jegadeesh, and C. Pereira, "Bio inspired synthesis of monodispersed silver nano particles using Sapindus emarginatus pericarp extract-study of antibacterial efficacy," Journal of Saudi Chemical Society, 2015.

[14] A. G. Ingale and A. N. Chaudhari, "Biogenic synthesis of nanoparticles and potential applications: an eco- friendly approach," Journal of Nanomedicine \& Nanotechnology, vol. 4, article 165, 2013.

[15] S. I. Hashoosh, A. M. A. Fadhil, and N. K. Al-Ani, "Production of Ag nanoparticles using Aloe vera extract and its antimicrobial activity," Journal of Al-Nahrain University, vol. 17, no. 2, pp. 165172, 2014.

[16] M. J. Firdhouse and P. Lalitha, "Apoptotic efficacy of biogenic silver nanoparticles on human breast cancer MCF-7 cell lines," Progress in Biomaterials, vol. 4, no. 2-4, pp. 113-121, 2015.

[17] D. A. Kumar, V. Palanichamy, and S. M. Roopan, "Green synthesis of silver nanoparticles using Alternanthera dentata leaf extract at room temperature and their antimicrobial activity," Spectrochimica Acta Part A: Molecular and Biomolecular Spectroscopy, vol. 127, pp. 168-171, 2014.

[18] K. D. Arunachalam and S. K. Annamalai, "Chrysopogon zizanioides aqueous extract mediated synthesis characterization of crystalline silver and gold nanoparticles for biomedical applications," International Journal of Nanomedicine, vol. 8, no. 1, pp. 2375-2384, 2013.

[19] J. Palanivelu, M. M. Kunjumon, A. Suresh, A. Nair, and C. Ramalingam, "Green synthesis of silver nanoparticles from Dracaena mahatma leaf extract and its antimicrobial activity," Journal of Pharmaceutical Sciences and Research, vol. 7, no. 9, pp. 690-695, 2015.

[20] S. Bhakya, S. Muthukrishnan, M. Sukumaran, and M. Muthukumar, "Biogenic synthesis of silver nanoparticles and their antioxidant and antibacterial activity," Applied Nanoscience, vol. 6, no. 5, pp. 755-766, 2016.

[21] C. Kamaraj, G. Rajakumar, A. A. Rahuman et al., "Feeding deterrent activity of synthesized silver nanoparticles using Manilkara zapota leaf extract against the house fly, Musca domestica (Diptera: Muscidae)," Parasitology Research, vol. 111, no. 6, pp. 2439-2448, 2012.

[22] R. Sukirtha, K. M. Priyanka, J. J. Antony et al., "Cytotoxic effect of Green synthesized silver nanoparticles using Melia azedarach against in vitro HeLa cell lines and lymphoma mice model," Process Biochemistry, vol. 47, no. 2, pp. 273-279, 2012.

[23] D. Mubarak Ali, N. Thajuddin, K. Jeganathan, and M. Gunasekaran, "Plant extract mediated synthesis of silver and gold nanoparticles and its antibacterial activity against clinically isolated pathogens," Colloids and Surfaces B: Biointerfaces B, vol. 85, no. 2, pp. 360-365, 2011.

[24] R. Sankar, A. Karthik, A. Prabu, S. Karthik, K. S. Shivashangari, and V. Ravikumar, "Origanum vulgare mediated biosynthesis of silver nanoparticles for its antibacterial and anticancer activity," Colloids and Surfaces B: Biointerfaces, vol. 108, pp. 80-84, 2013.

[25] P. Kathireswari, S. Gomathi, and K. Saminathan, "Plant leaf mediated synthesis of silver nanoparticles using Phyllanthus niruri and its antibacterial activity against multi drug resistant human pathogens," International Journal of Current Microbiology and Applied Sciences, vol. 3, no. 3, pp. 960-968, 2014. 
[26] M. J. Firdhouse, P. Lalitha, and S. K. Sripathi, "Novel synthesis of silver nanoparticles using leaf ethanol extract of Pisonia grandis (R. Br)," Der Pharma Chemica, vol. 4, no. 6, pp. 2320-2326, 2012.

[27] P. Velmurugan, M. Cho, S.-S. Lim et al., "Phytosynthesis of silver nanoparticles by Prunus yedoensis leaf extract and their antimicrobial activity," Materials Letters, vol. 138, pp. 272-275, 2015.

[28] M. Bhagat, S. Rajput, S. Arya, S. Khan, and P. Lehana, "Biological and electrical properties of biosynthesized silver nanoparticles," Bulletin of Materials Science, vol. 38, no. 5, pp. 1253-1258, 2015.

[29] S. Arokiyaraj, S. Vincent, M. Saravanan, Y. Lee, Y. K. Oh, and K. H. Kim, "Green synthesis of silver nanoparticles using Rheum palmatum root extract and their antibacterial activity against Staphylococcus aureus and Pseudomonas aeruginosa," Artificial Cells, Blood Substitutes, and Biotechnology, 2016.

[30] N. L. Gavade, A. N. Kadam, M. B. Suwarnkar, V. P. Ghodake, and K. M. Garadkar, "Biogenic synthesis of multi-applicative silver nanoparticles by using Ziziphus Jujuba leaf extract," Spectrochimica Acta Part A: Molecular and Biomolecular Spectroscopy, vol. 136, pp. 953-960, 2015.

[31] D. Aichner and M. Ganzera, "Analysis of anthraquinones in rhubarb (Rheum palmatum and Rheum officinale) by supercritical fluid chromatography," Talanta, vol. 144, pp. 1239-1244, 2015.

[32] L. Zhang, J.-H. Chang, B.-Q. Zhang et al., "The pharmacokinetic study on the mechanism of toxicity attenuation of rhubarb total free anthraquinone oral colon-specific drug delivery system," Fitoterapia, vol. 104, pp. 86-96, 2015.

[33] Q. Zheng, H. F. Wu, J. Guo et al., "Review of rhubarbs: chemistry and pharmacology," Chinese Herbal Medicines, vol. 5, no. 1, pp. 9-32, 2013.

[34] X. Ren, X. Meng, D. Chen, F. Tang, and J. Jiao, "Using silver nanoparticle to enhance current response of biosensor," Biosensors and Bioelectronics, vol. 21, no. 3, pp. 433-437, 2005.

[35] M. Layani and S. Magdassi, "Flexible transparent conductive coatings by combining self-assembly with sintering of silver nanoparticles performed at room temperature," Journal of Materials Chemistry, vol. 21, no. 39, pp. 15378-15382, 2011.

[36] J. Li, L. Liu, D. Zhang, D. Yang, J. Guo, and J. Wei, "Fabrication of polyaniline/silver nanoparticles/multi-walled carbon nanotubes composites for flexible microelectronic circuits," Synthetic Metals, vol. 192, pp. 15-22, 2014.

[37] P. R. S. Reddy, S. Eswaramma, K. S. V. Krishna Rao, and Y. I. Lee, "Dual responsive pectin hydrogels and their silver nanocomposites: swelling studies, controlled drug delivery and antimicrobial applications," Bulletin of the Korean Chemical Society, vol. 35, no. 8, pp. 2391-2399, 2014.

[38] N. Roy, A. Gaur, A. Jain, S. Bhattacharya, and V. Rani, "Green synthesis of silver nanoparticles: an approach to overcome toxicity," Environmental Toxicology and Pharmacology, vol. 36, no. 3, pp. 807-812, 2013.

[39] S. Prabhu and E. K. Poulose, "Silver nanoparticles: mechanism of antimicrobial action, synthesis, medical applications, and toxicity effects," International Nano Letters, vol. 2, no. 1, article 32, 10 pages, 2012.

[40] Y. Sun and Y. Xia, "Shape-controlled synthesis of gold and silver nanoparticles," Science, vol. 298, no. 5601, pp. 2176-2179, 2002. 

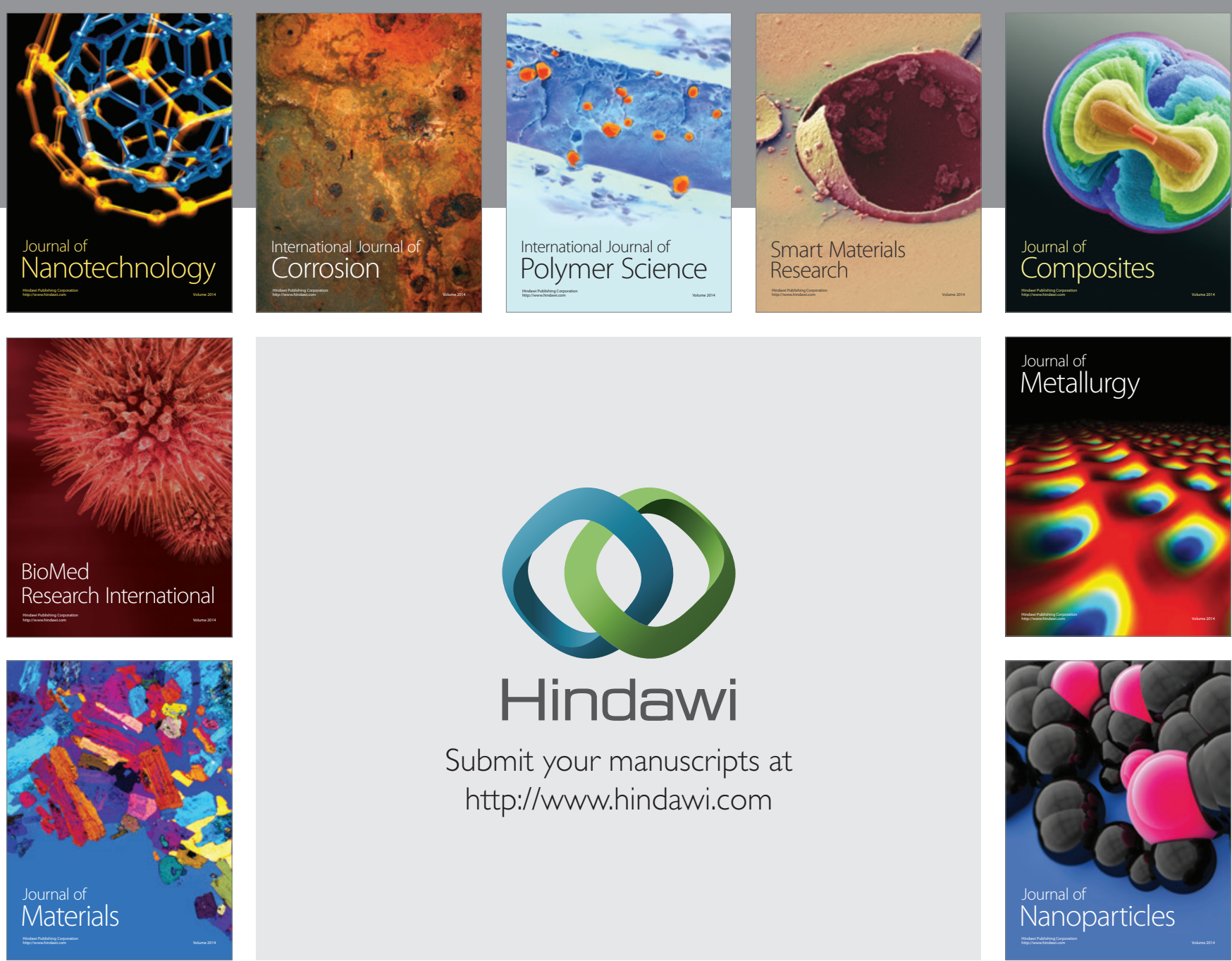

\section{Hindawi}

Submit your manuscripts at

http://www.hindawi.com

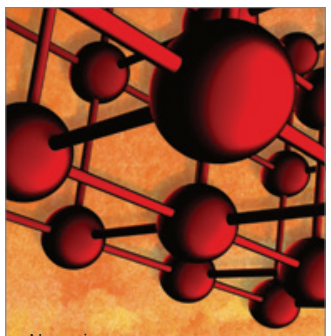

Materials Science and Engineering
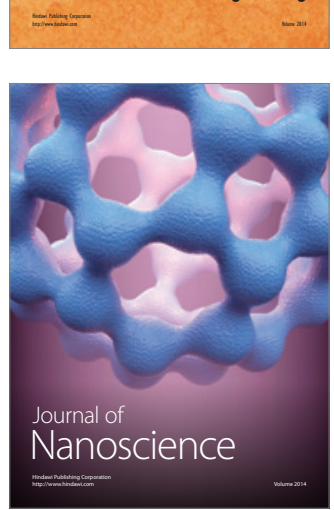
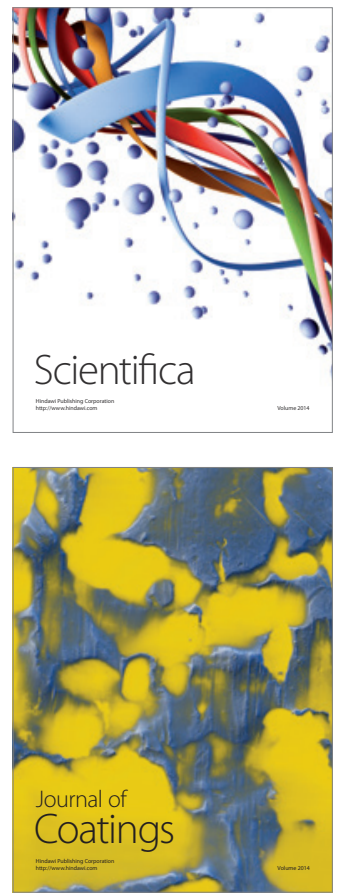
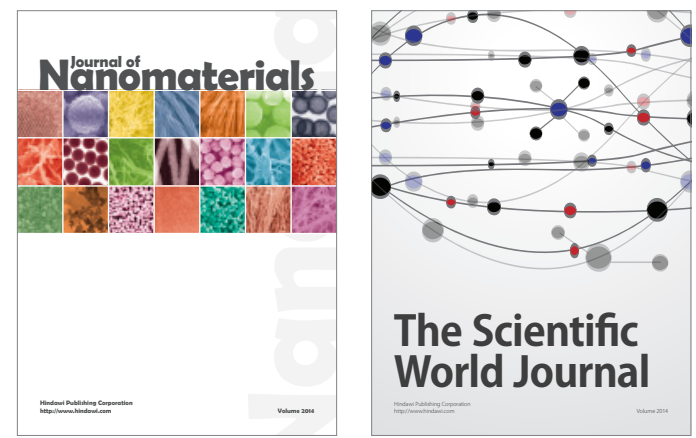

The Scientific World Journal
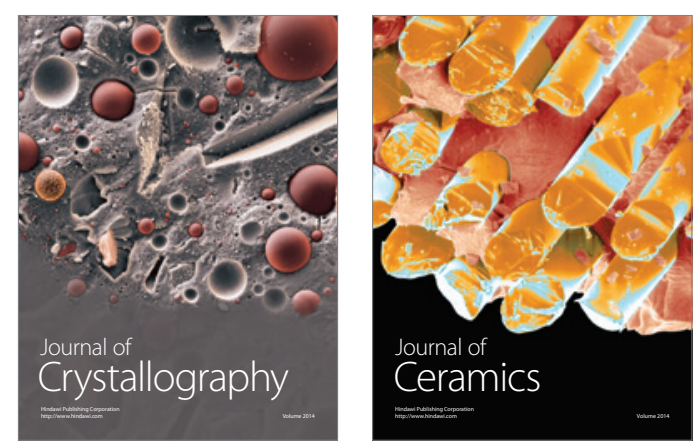
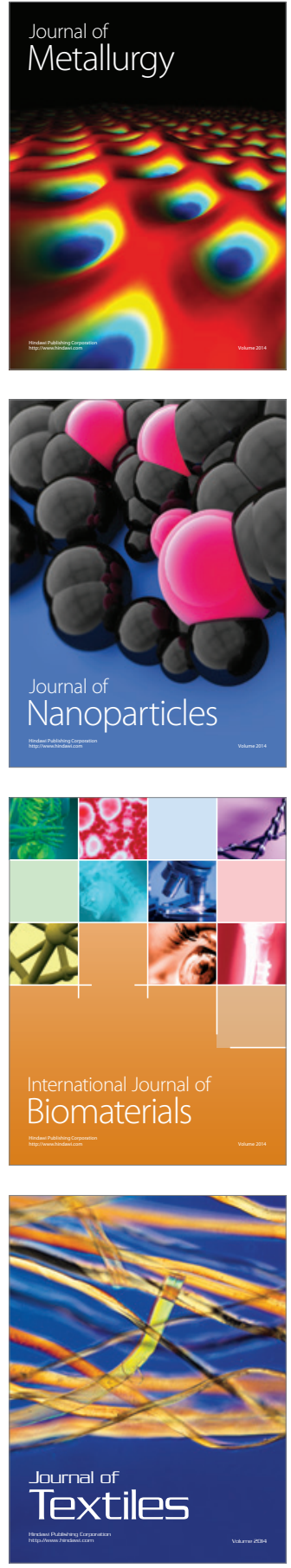